\title{
Digestibilidade dos compostos nitrogenados insolúveis em detergente ácido em bovinos manejados em pastagem de capim-braquiária
}

\author{
Edenio Detmann ${ }^{1^{*}}$, Mário Fonseca Paulino ${ }^{1^{*}}$, José Fernando Coelho da Silva ${ }^{2^{*}}$, Sebastião de \\ Campos Valadares Filho ${ }^{1^{*}}$, Joanis Tilemahos Zervoudakis ${ }^{3}$, Luciano da Silva Cabral ${ }^{3}$, \\ Paulo Roberto Cecon ${ }^{*}$, Rogério de Paula Lana ${ }^{1^{*}}$
}

\footnotetext{
${ }^{1}$ Departamento de Zootecnia - Universidade Federal de Viçosa, Viçosa-MG.

2 Universidade Estadual do Norte Fluminense, Campos dos Goytacazes-RJ.

${ }^{3}$ Universidade Federal de Mato Grosso, Cuiabá-MT.

${ }^{4}$ Departamento de Informática - Universidade Federal de Viçosa, Viçosa-MG.

* Bolsista do CNPq.
}

RESUMO - Objetivou-se neste estudo avaliar as digestibilidades total e parcial dos compostos nitrogenados insolúveis em detergente ácido (NIDA) em bovinos em pastejo. Foram utilizados cinco novilhos mestiços Holandês x Zebu (24 meses de idade e $304 \mathrm{~kg}$ de PV), canulados no esôfago, rúmen e abomaso, manejados em cinco piquetes de Brachiaria decumbens (0,34 ha), recebendo ou não suplementação com concentrado. O experimento foi realizado em quatro períodos experimentais de 21 dias, entre agosto e novembro de 2000. A avaliação da forragem selecionada pelos animais foi feita em amostras de extrusa esofágica e a estimativa do consumo e dos fluxos fecais e abomasais de MS e NIDA, foram estimados por intermédio de indicadores interno e externo. A avaliação estatística da digestibilidade do NIDA foi conduzida por ajustamento de equação de regressão linear, desconsiderando o parâmetro intercepto e utilizando-se como variáveis independente e dependente as estimativas de influxo e efluxo de NIDA, respectivamente. Os desvios do coeficiente de regressão a partir do valor paramétrico 1,0 foram considerados estimativas de digestibilidade. A comparação entre o consumo e os fluxos abomasal e fecal de NIDA indicou haver digestibilidade desta fração em nível total, atribuída exclusivamente a eventos intestinais (30,7\%), uma vez que não foi observada digestibilidade no compartimento ruminal. Esse comportamento indica que o teor de NIDA de um alimento é somente indicador, e não preditor, da digestibilidade potencial dos compostos nitrogenados totais.

Palavras-chave: Brachiaria decumbens, consumo, fracionamento de compostos nitrogenados, NIDA

\section{Digestibility of acid detergent insoluble nitrogen in cattle grazing signalgrass}

\begin{abstract}
The objective of this trial was to investigate ruminal, intestinal and total tract digestibility of acid detergent insoluble nitrogen (ADIN) in grazing cattle. Five Holstein x Zebu steers averaging $304 \mathrm{~kg}$ of body weight and 24 months of age and fitted with esophageal, ruminal and abomasal cannulas were used in this study. Animals were maintained in five 0.34-ha paddocks of Brachiaria decumbens with or without concentrate supplementation. The experiment was conducted from August to November of 2000 using four 21-days experimental periods. Evaluation of the forage ingested by the animals was done by collecting esophageal extrusa samples. The flow of fecal and abomasal dry matter was estimated by using both internal and external markers. Statistical analysis of ADIN digestibility was conducted by adjustment of the linear regression equation with no intercept in the model and using ADIN inflow as independent variable and ADIN outflow as dependent variable. The deviation of the regression coefficient from the parametrical value 1.0 was considered to be digestible matter. Comparison between intake and abomasum and fecal flows of ADIN indicated that the observed total tract digestibility (30.7\%) of this nitrogen fraction occurred exclusively in the intestine. Therefore, ADIN content of feeds can be considered only as an indicator but not as a predictor of nitrogen compounds potential digestibility.
\end{abstract}

Key Words: ADIN, Brachiaria decumbens, intake, nitrogenous compounds fractions

\section{Introdução}

A fração dos compostos nitrogenados ligada à porção insolúvel em detergente ácido da parede celular (NIDA) tem sido empregada como preditor do potencial de aprovei- tamento protéico por alguns dos principais sistemas nutricionais, como o sistema britânico (AFRC, 1993) e o Cornell Net Carbohydrate and Protein System (Sniffen et al., 1992), no sentido de que, embora composta, em parte, por aminoácidos (Muscato et al., 1983), não apresenta 
disponibilidade aos microrganismos ruminais ou digestibilidade intestinal (Sniffen et al., 1992).

Por outro lado, diversos estudos têm apontado controvérsias sobre a disponibilidade de NIDA ao longo do trato gastrintestinal dos ruminantes, com relatos de estimativas de digestibilidade substancialmente desviadas da nulidade.

Esse comportamento tem sido evidenciado em alimentos ricos em taninos (Waters et al., 1992) ou que sofreram danos por calor (Van Soest, 1994), indicando que esta fração pode ser subdividida em duas subfrações distintas, sendo uma potencialmente digestível (Broderick, 1995).

Assim, especula-se que o NIDA, embora indicador do teor total de compostos nitrogenados não-utilizáveis pelo animal, não possa ser empregado para estimação da digestibilidade potencial dos compostos nitrogenados (NRC, 2001). Contudo, esse comportamento não tem sido avaliado e/ou validado em sistemas de alimentação em pastejo no Brasil, ocasionando um déficit de informações acerca da efetividade do NIDA como parâmetro de avaliação dos compostos nitrogenados dos alimentos.

Desta forma, realizou-se este estudo com o objetivo de avaliar as digestibilidades total e parcial do NIDA em bovinos manejados em pastagem de capim-braquiária.

\section{Material e Métodos}

O experimento foi realizado na Central de Experimentação, Pesquisa e Extensão do Triângulo Mineiro da Universidade Federal de Viçosa (CEPET/UFV), em Capinópolis, na região do Pontal do Triângulo, estado de Minas Gerais.

Foram utilizados cinco bovinos machos, não-castrados, $1 / 2$ Holandês x Zebu, com 24 meses de idade e peso médio inicial de $304 \mathrm{~kg}$, fistulados no esôfago, rúmen e abomaso, distribuídos em cinco piquetes de Brachiaria decumbens Stapf (0,34 ha, providos de bebedouro e comedouro), recebendo ou não suplementação alimentar.

Os suplementos, constituídos de fubá de milho, grão de soja integral, uréia, sulfato de amônia e mistura mineral, foram balanceados para apresentar 12, 16, 20 e 24\% de PB, com base na matéria natural. Fixou-se, no balanceamento dos suplementos, em 3:1 a relação entre os compostos nitrogenados oriundos dos alimentos concentrados e aqueles fornecidos pela mistura uréia/sulfato de amônia (9:1). Os suplementos foram fornecidos diariamente, às $10 \mathrm{~h}$, na quantidade de $4 \mathrm{~kg} /$ animal, proporcionando-se acesso irrestrito à água e à mistura mineral em todos os tratamentos.

O experimento foi realizado entre agosto e novembro de 2000 e constou de quatro períodos experimentais de 21 dias, sendo os sete primeiros destinados à adaptação dos animais. Cada animal foi manejado em um único piquete, de modo que aqueles sob suplementação alimentar fossem redistribuídos de forma aleatória ao início de cada período experimental.

A avaliação da forragem ingerida pelos animais foi realizada em amostras de extrusa esofágica, no $5 \underline{0}$ e $20^{0}$ dias de cada período experimental. Às $20 \mathrm{~h}$ do dia anterior, os animais foram recolhidos ao curral de contenção, localizado nas proximidades dos piquetes experimentais, de forma a permitir jejum prévio de aproximadamente 12 horas, no intuito de evitar possíveis problemas de regurgitação durante a coleta. Às $8 \mathrm{~h}$, os animais foram equipados com bolsas coletoras de fundo telado, acopladas abaixo da fístula esofágica, e conduzidos a seus respectivos piquetes, onde pastejaram livremente por cerca de 40 minutos. Posteriormente, foram recolhidos para a retirada das bolsas e reconduzidos imediatamente à área de pastejo. As amostras de extrusa foram colocadas em sacos plásticos, identificadas e congeladas a $-20^{\circ} \mathrm{C}$.

O procedimento para estimação da excreção fecal baseou-se no fornecimento de indicador externo, em dose única (France et al., 1988), empregando-se como indicador o cromo mordentado à fibra, produzido conforme descrição de Udén et al. (1980). A base fibrosa para produção do indicador foi retirada de amostras de simulação manual de pastejo, obtidas entre o 5 o e o $10^{0}$ dia de cada período experimental. Para simulação do processo inicial de mastigação, as amostras de pastejo simulado foram submetidas a um processo tríplice de moagem em moinho de faca, sem peneira. Foram fornecidos às $8 \mathrm{~h}$ do $16^{0} \mathrm{o}$ dia do período experimental $100 \mathrm{~g}$ de fibra mordentada por animal. As amostras fecais foram tomadas nos tempos $0,6,12,18,24$, $30,36,42,48,60,84,108$ e 144 horas após o fornecimento do indicador (Detmann et al., 2001) e, posteriormente, foram secas em estufa de ventilação forçada $\left(60^{\circ} \mathrm{C}-72\right.$ horas $)$, sendo processadas em moinho de faca com peneira de $1 \mathrm{~mm}$ e acondicionadas individualmente em frascos de polietileno. Posteriormente, retiraram-se de cada amostra alíquotas de $3 \mathrm{~g}$, compostas por animal/período.

As amostras de fezes e fibra mordentada foram analisadas individualmente quanto aos teores de MS (AOAC, 1990) e cromo (Willians et al., 1962). Procedeu-se ao ajustamento às curvas de excreção fecal do indicador, por meio do procedimento de Gauss Newton (Souza, 1998), do modelo nãolinear, gama 2, tempo-dependente (France et al., 1988):

$$
C_{t}=Z(t-\tau) L^{2} \exp [-L(t-\tau)]
$$

em que: $\mathrm{C}_{\mathrm{t}}=$ concentração fecal do indicador no tempo " $\mathrm{t}$ " (ppm); $\mathrm{t}=$ tempo (horas) após o fornecimento do indicador; $\mathrm{L}=$ parâmetro taxa tempo-dependente relativo ao fluxo ruminal de partículas $\left(\mathrm{h}^{-1}\right) ; \mathrm{Z}=$ parâmetro sem interpretação 
biológica direta $(\mathrm{ppm} \cdot \mathrm{h})$; e $\tau=$ tempo (horas) decorrido entre a aplicação e o aparecimento do indicador nas fezes.

As estimativas de excreção fecal foram obtidas por meio da equação descrita por France et al. (1988):

$$
E F=(D / Z) \times 24
$$

em que: $E F$ = excreção fecal $(\mathrm{kg} / \mathrm{dia}) ; \mathrm{D}=$ dose de cromo (mg); e Z como definido anteriormente.

Do 8 a ao 13 o dia do período experimental, realizaram-se coletas de digesta abomasal, as quais serviram como base para estimação do efluxo ruminal. A amostragem seguiu a distribuição: $8^{\mathrm{o}}$ dia $=18 \mathrm{~h} ; 9^{\circ} \mathrm{o}$ dia $=16 \mathrm{~h} ; 10^{\mathrm{o}} \mathrm{dia}=14 \mathrm{~h}$; $11^{\circ} \mathrm{dia}=12 \mathrm{~h}, 12^{\circ} \mathrm{dia}=10 \mathrm{~h}$ e $13^{\circ} \mathrm{o}$ dia $=8 \mathrm{~h}$. Após secagem em estufa de ventilação forçada $\left(60^{\circ} \mathrm{C}-72\right.$ horas $)$, as amostras foram processadas em moinho de faca com peneira de $1 \mathrm{~mm}$, compostas proporcionalmente, com base no peso seco ao ar, e armazenadas em frascos de polietileno para análise posterior.

A estimação do consumo voluntário e do fluxo de digesta abomasal foi realizada utilizando-se como indicador interno a fibra em detergente neutro indigestível (FDNi), determinada nas amostras de suplementos, nas compostas abomasais fecais e nas extrusas esofágicas por meio de procedimento de digestibilidade in situ por 144 horas (Lippke et al., 1986). O consumo total de NIDA e seus fluxos diário abomasal e fecal foram estimados como o produto de sua concentração nos alimentos ingeridos e nas amostras de digesta abomasal e de fezes por seus respectivos consumos e fluxos.

As amostras de suplementos, compostas fecais e extrusas foram avaliadas quanto aos teores de MS, PB, MO, EE (AOAC, 1990), FDN e FDA (Van Soest \& Robertson, 1985) (Tabela 1). Os teores de NIDA foram estimados nos resíduos obtidos após o tratamento das amostras em detergente ácido pelo procedimento de Kjeldhal (Licitra et al., 1996) (Tabela 1).

O experimento foi implementado em delineamento em quadrado latino $4 \times 4$, balanceado para efeitos residuais de tratamentos (Cochran \& Cox, 1957), no qual se incorporou como tratamentos a suplementação com diferentes níveis de proteína.

Ao tratamento controle (sem suplementação), destinou-se o mesmo animal, no mesmo piquete, durante todo o experimento, sendo utilizado como medida de comparação descritiva em relação ao delineamento. Maiores detalhes sobre parâmetros de consumo, digestibilidade e metabolismo em relação a inferências comparativas entre tratamentos foram relatados por Detmann et al. (2005a) e (2005b).

Sob a pressuposição de ausência de contribuição endógena de compostos nitrogenados insolúveis em
Tabela 1 - Composição química da extrusa e dos suplementos, com base na MS

Table 1 - Chemical composition of esophageal extrusa and supplements on dry matter basis

\begin{tabular}{|c|c|c|c|c|c|c|}
\hline \multirow[b]{2}{*}{ Item } & \multicolumn{2}{|c|}{ Extrusa } & \multicolumn{4}{|c|}{$\begin{array}{c}\text { Suplemento } \\
\text { Supplement }\end{array}$} \\
\hline & $\begin{array}{l}\text { Média } \\
\text { Mean }\end{array}$ & $\begin{array}{c}\mathrm{EPM}^{5} \\
S E M\end{array}$ & 12 & 16 & 20 & 24 \\
\hline $\begin{array}{l}\text { MS (\%) } \\
D M(\%)\end{array}$ & 12,82 & 0,168 & 87,03 & 87,34 & 87,37 & 87,68 \\
\hline $\begin{array}{l}\mathrm{MO}^{1} \\
O M\end{array}$ & 885,7 & 4,527 & 978,4 & 971,4 & 966,6 & 962,4 \\
\hline $\begin{array}{l}\mathrm{EE}^{1} \\
\mathrm{~PB}^{1}\end{array}$ & $\begin{array}{r}19,2 \\
109,9\end{array}$ & $\begin{array}{l}0,236 \\
8,832\end{array}$ & $\begin{array}{r}48,3 \\
147,0\end{array}$ & $\begin{array}{r}62,3 \\
188,2\end{array}$ & $\begin{array}{r}79,6 \\
229,9\end{array}$ & $\begin{array}{r}84,9 \\
274,0\end{array}$ \\
\hline $\begin{array}{l}C P \\
\mathrm{CT}^{1,2}\end{array}$ & 756,5 & 10,162 & 783,1 & 720,9 & 657,1 & 603,5 \\
\hline $\begin{array}{l}T C \\
\mathrm{FDN}^{1} \\
N D F\end{array}$ & 564,4 & 14,635 & 74,8 & 80,0 & 87,1 & 98,8 \\
\hline $\begin{array}{l}\mathrm{FDNi}^{1} \\
i N D F\end{array}$ & 121,0 & 8,348 & 6,3 & 5,9 & 7,7 & 6,8 \\
\hline $\begin{array}{l}\mathrm{CNF}^{1,3} \\
N F C\end{array}$ & 192,1 & 5,385 & 708,3 & 640,8 & 570,0 & 504,7 \\
\hline $\begin{array}{l}\mathrm{FDA}^{1} \\
A D F\end{array}$ & 250,5 & 6,148 & 21,7 & 36,0 & 51,9 & 65,6 \\
\hline $\begin{array}{l}\text { NIDA }^{4} \\
A D I N\end{array}$ & 4,7 & 0,492 & 0,7 & 1,5 & 1,6 & 1,8 \\
\hline
\end{tabular}

$1 \mathrm{~g} / \mathrm{kg} \mathrm{MS}(\mathrm{g} / \mathrm{kg}$ of $D M)$.

$2 \mathrm{CT}=\mathrm{MO}-(\mathrm{PB}+\mathrm{EE})(T C=O M-(C P+E E))$.

${ }^{3} \mathrm{CNF}=\mathrm{CT}-\mathrm{FDN}($ NFC $=T C-N D F)$.

$4 \%$ dos compostos nitrogenados totais (\% of total nitrogenous compounds).

5 EPM = erro-padrão da média (SEM = standard error of mean).

6 Os valores listados referem-se ao nível esperado de PB no suplemento, com base na matéria natural (Expected levels of CP in the supplements on as-fed basis).

detergente ácido, as avaliações estatísticas da digestibilidade do NIDA foram conduzidas de forma independente aos tratamentos aplicados, pelo ajustamento de equação de regressão, desconsiderando o parâmetro intercepto e adotando o influxo e o efluxo de NIDA como variáveis independente e dependente, respectivamente, segundo o modelo:

$$
Y_{i}=\beta X_{i}+e_{i}
$$

em que: $\mathrm{Y}_{\mathrm{i}}=$ efluxo de NIDA (g/dia), tomado em termos de digesta abomasal, para avaliação de digestibilidade ruminal, em termos fecais, para avaliação das digestibilidades total e intestinal; $\mathrm{X}_{\mathrm{i}}=$ influxo diário de NIDA (g/dia) dos alimentos ingeridos para avaliação das digestibilidades ruminal e total e da digesta abomasal, para avaliação da digestibilidade intestinal; $\beta=$ coeficiente de inclinação da reta; e $e_{i}=$ erro aleatório, associado a cada observação, pressuposto NID $\left(0, \sigma^{2}\right)$.

Para avaliação da ocorrência de digestibilidade, conduziram-se as análises estatísticas sob as seguintes hipóteses $(\alpha=0,10)$ :

$$
\begin{aligned}
& H_{0}: \beta=1 \\
& H_{a}: \beta \neq 1
\end{aligned}
$$


Sob o caso de não-rejeição de $\mathrm{H}_{0}$, concluiu-se pela ausência de digestibilidade. Nos casos de não-aceitação da hipótese de nulidade, estimou-se a digestibilidade pela equação:

$$
D I G=(1-\hat{\beta}) \times 100
$$

em que: $\mathrm{DIG}=$ digestibilidade, como porcentagem do total que chegou ao segmento avaliado; $\hat{\beta}=$ estimativa do coeficiente angular da equação ajustada; e "1" = valor paramétrico para o coeficiente angular sob a pressuposição de $\mathrm{H}_{0}$ ser verdadeira.

\section{Resultados e Discussão}

O consumo, o fluxo abomasal e a excreção fecal de NIDA observados no experimento são apresentados na Tabela 2 e a avaliação das relações entre influxo e efluxo de NIDA, na Tabela 3 e nas Figuras 1, 2 e 3.

Considerando todo o trato gastrintestinal, verificou-se a ocorrência de digestibilidade desta fração $(25,10 \%)$ $(\mathrm{P}<0,01)$, confirmada pela elevada concentração de pontos abaixo da reta indicadora de igualdade de fluxos $(\mathrm{X}=\mathrm{Y})$ (Figura 1). Por outro lado, a avaliação dos fluxos de forma parcial não permitiu a detecção de influência significativa do compartimento ruminal $(\mathrm{P}>0,10)$ sobre a digestibilidade do NIDA (Tabela 3; Figura 2), de modo que todo o desaparecimento foi atribuído ao segmento intestinal $(30,74 \%)$ $(\mathrm{P}<0,01)$ (Tabela 3; Figura 3).

Vários autores têm relatado digestibilidades elevadas para NIDA, notadamente em alimentos submetidos a tratamentos térmicos (Waters et al., 1992; Broderick et al., 1993; Nakamura et al., 1994a, b; Van Soest, 1994). Nesses casos, observa-se ampliação dos teores naturais de NIDA dos alimentos, em decorrência da formação de produtos da reação de Maillard (Nakamura et al., 1994a), a qual, por meio de interações de açúcares redutores e proteína, responde, parcialmente, por reduções na degradabilidade ruminal da proteína (Yang et al., 1993). A esta nova porção tem-se

Tabela 2 - Médias de quadrados mínimos para o consumo e os fluxos abomasal e fecal de NIDA (g/dia)

Table 2 - $\quad$ Least square means for intake and fecal and abomasal flows of acid detergent insoluble nitrogen (g/day)

\begin{tabular}{lc}
\hline Item & $\begin{array}{c}\text { Média } \pm \mathrm{EPM}^{1} \\
\text { Mean } \pm \text { SEM }\end{array}$ \\
\hline Consumo (Intake) & $6,8 \pm 0,48$ \\
Fluxo abomasal (Abomasal flow) & $6,1 \pm 0,30$ \\
Fluxo fecal (Fecal flow) & $5,2 \pm 0,29$ \\
\hline
\end{tabular}

1 EPM = erro-padrão da média (SEM = standard error of mean).

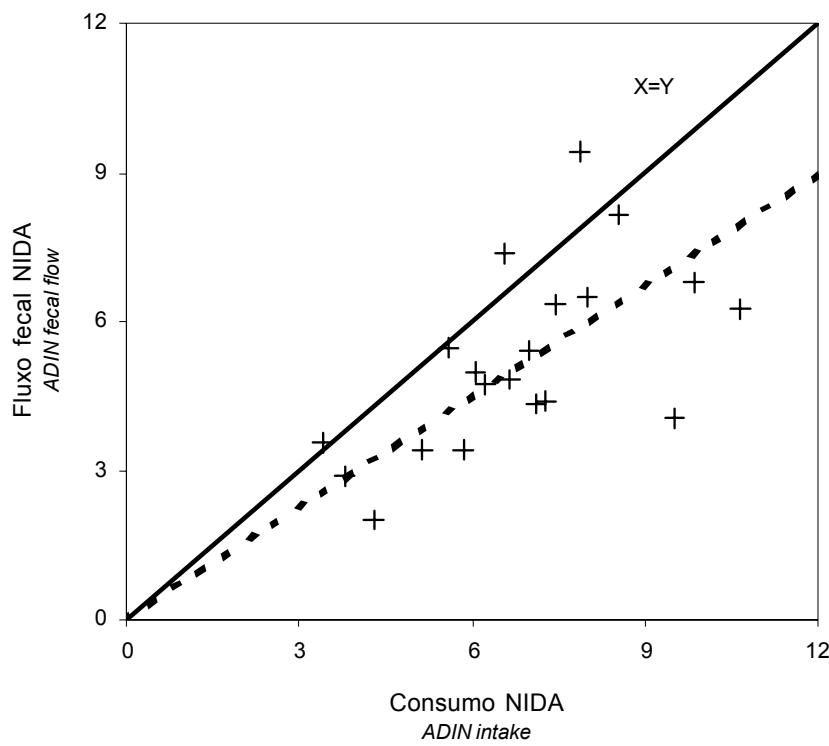

Figura 1 - Relação consumo x fluxo fecal (g/dia) de NIDA (a linha tracejada corresponde à reta de quadrados mínimos).

Figure 1 - Intake versus fecal flow (g/day) of acid detergent insoluble nitrogen (ADIN) (the dashed line represents the least square straight line).

Tabela 3 - Estimativas e limites do intervalo de confiança, a 95\% de probabilidade $\left(\mathrm{IC}_{95 \%}\right)$, para o coeficiente de inclinação e os níveis descritivos de probabilidade para a hipótese de nulidade para a relação influxo x efluxo de NIDA (g/dia) em diferentes segmentos do trato gastrintestinal

Table 3 - Estimates and $95 \%$ confidence interval $\left(\mathrm{Cl}_{95 \%}\right)$ for the slope coefficient and descriptive levels of probability for the null hypothesis of inflow versus outflow of ADIN (g/day) in different segments of the gastrointestinal tract

\begin{tabular}{|c|c|c|c|c|}
\hline \multirow[t]{2}{*}{$\begin{array}{l}\text { Segmento } \\
\text { Segment }\end{array}$} & \multirow[t]{2}{*}{$\begin{array}{c}\text { Estimativa coeficiente de inclinação } \\
\text { Estimate of slope coefficient }\end{array}$} & \multicolumn{2}{|c|}{$\begin{array}{l}\text { Limite } \mathrm{IC}_{95 \%} \\
\qquad I_{95 \%}\end{array}$} & \multirow[t]{2}{*}{$\begin{array}{l}\text { Valor-P } \\
P \text {-value }\end{array}$} \\
\hline & & $\begin{array}{c}\text { Superior } \\
\text { Higher }\end{array}$ & $\begin{array}{l}\text { Inferior } \\
\text { Lower }\end{array}$ & \\
\hline Total & 0,7490 & 0,8476 & 0,6504 & 0,0001 \\
\hline Total & & & & \\
\hline Ruminal & 0,8175 & 1,0447 & 0,5903 & 0,1090 \\
\hline $\begin{array}{l}\text { Ruminal } \\
\text { Intestinal }\end{array}$ & 0,6926 & 0,9053 & 0,4799 & 0,0070 \\
\hline
\end{tabular}

Intestinal

${ }^{1} H_{0}: \beta=1 ; H_{a}: \beta \neq 1$. 


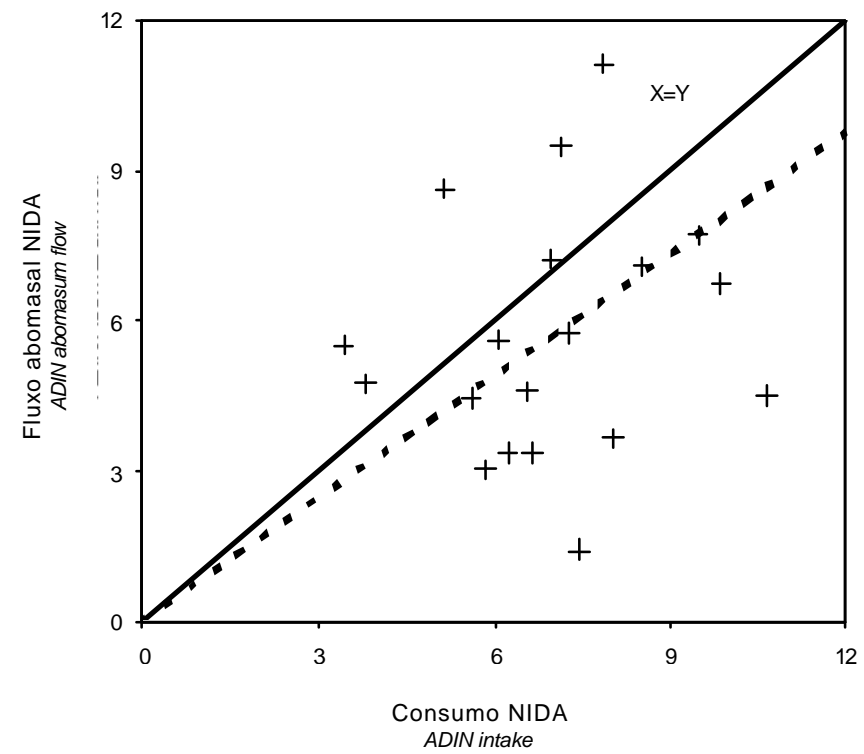

Figura 2 - Relação consumo x fluxo abomasal (g/dia) de NIDA (a linha tracejada corresponde à reta de quadrados mínimos).

Figure 2 - Intake versus abomasal flow (g/day) of acid detergent insoluble nitrogen (ADIN) (the dashed line represents the least square straight line).

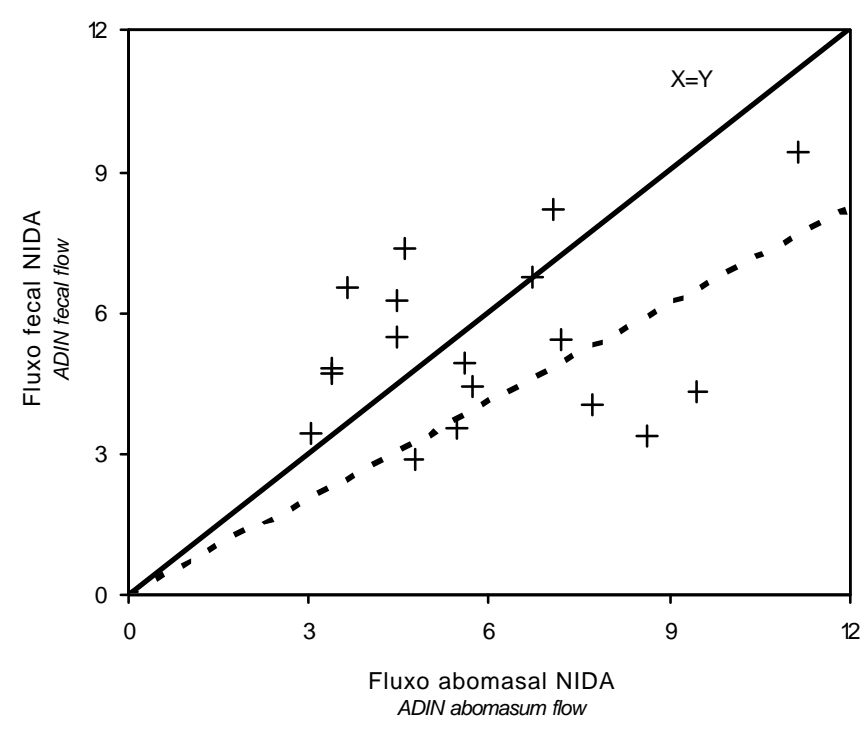

Figura 3 - Relação entre os fluxos abomasal e fecal (g/dia) de NIDA (a linha tracejada corresponde à reta de quadrados mínimos).

Figure 3 - Abomasal versus fecal flows (g/day) of acid detergent insoluble nitrogen (ADIN) (the dashed line represents the least square straight line).

atribuído as observações acerca do desaparecimento de NIDA no trato gastrintestinal de ruminantes e, embora ainda existam incertezas sobre o local de digestão do NIDA gerado por aquecimento (NRC, 2001), Nakamura et al. (1994b) afirmaram haver digestão em nível de intestino, sem, contudo, ocorrer aproveitamento para o metabolismo animal. Estas características tornam o NIDA preditor de baixa acurácia para o potencial de degradação dos compostos protéicos dos alimentos (Nakamura et al., 1994a).

Em primeira instância, o comportamento observado neste trabalho poderia ser atribuído, pelo menos em parte, ao procedimento de secagem adotado $\left(60^{\circ} \mathrm{C}\right.$ por 72 horas). Ao uso de secagem por ventilação forçada, atribuem-se elevações nos teores de componentes da parede celular, as quais parecem ser mais evidentes em extrusas esofágicas (Acosta $\&$ Kothman, 1978) e em forragens de menor grau de maturidade (Burritt et al., 1988), quando comparado ao procedimento de liofilização. No entanto, alguns argumentos não permitem confirmar concreta e completamente esta hipótese.

A ocorrência da reação de Maillard é verificada somente na presença de açúcares com poder redutor (Nakamura et al., 1994a; Van Soest, 1994), os quais consistem, basicamente, de mono e oligossacarídeos (Nelson \& Cox, 2000). Esses compostos concentram-se no conteúdo celular e possuem degradabilidade ruminal rápida e praticamente completa (Van Soest, 1994), não possibilitando, portanto, passagem quantitativamente significativa à porção posterior do trato gastrintestinal do ruminante.

Considerando esses argumentos e que todas as amostras utilizadas sofreram processo de secagem similar, con cluir-se-ia que produtos de Maillard seriam potencialmente formados somente em nível de extrusa esofágica, em virtude da presença de açúcares redutores.

Em termos quantitativos, a ocorrência dessa reação implicaria superestimação do consumo de NIDA, refletindo, por sua vez, um falso desaparecimento ruminal destes compostos, uma vez que a formação de produtos de Maillard não seria verificada em mesma intensidade em amostras de digesta abomasal. Entretanto, esse fato não foi verificado (Tabela 3, Figura 2) ( $\mathrm{P}>0,10)$, indicando que o fenômeno de desaparecimento de NIDA ao longo do trato gastrintestinal não pode ser atribuído à ocorrência da reação de Maillard em associação a procedimentos analíticos.

Por outro lado, incrementos no nitrogênio ligado à parede celular decorrentes de aquecimento não obrigatoriamente resultam em formação de NIDA, o qual só é produzido, sob essas circunstâncias, por intermédio da reação de Maillard (Van Soest, 1994), observada em maior intensidade sob concentrações elevadas de açúcares redutores (Clealeet al., 1987, citados por Nakamura et al., 1994a).

Além dos produtos de Maillard, o nitrogênio recuperado como NIDA pode conter complexos tanino-proteína e compostos nitrogenados ligados à lignina (Waters et al., 1992), podendo ser formado por 30 a $90 \%$ de nitrogênio oriundo de aminoácidos (Muscato et al., 1983). Algumas proteínas, normalmente ricas em glicina, apresentam intensa relação com a lignina da parede celular, podendo, 
possivelmente, ter função no processo de formação dos polímeros fenólicos (Iiyama et al., 1993). Em forragens imaturas, os compostos fenólicos componentes da lignina estão polimerizados em menor grau, fazendo com que fragmentos de baixo peso molecular sejam absorvidos e excretados via urina (Van Soest, 1994). Deste ponto de vista, questiona-se se as proteínas associadas à lignina poderiam apresentar tendência semelhante, o que justificaria o comportamento observado quanto ao desaparecimento intestinal de NIDA.

Em suma, nenhum dos argumentos apresentados pode ser descartado ou adotado concretamente. Portanto, sugere-se a condução de novos estudos para verificação da repetibilidade deste evento e a construção de teorias causativas concretas.

\section{Conclusões}

A fração dos compostos nitrogenados insolúveis em detergente ácido pode ser dividida em duas subfrações, sendo uma potencialmente digestível em nível intestinal, comprovando que o teor de NIDA de um alimento é somente indicador, e não preditor, da digestibilidade potencial dos compostos nitrogenados totais.

\section{Literatura Citada}

ACOSTA, R.A.; KOTHMAN, M.M. Chemical composition of esophageal-fistula forage samples as influenced by drying method and salivary leaching. Journal of Animal Science, v.47, n.3, p.691-698, 1978.

AGRICULTURAL AND FOOD RESEARCH COUNCIL - AFRC. Energy and protein requirements of ruminants. Wallingford: CAB International, 1993. 159p.

ASSOCIATION OF OFFICIAL ANALYTICAL CHEMISTRY AOAC. Official methods of analysis. 15.ed. Arlington: AOAC International, 1990. 1117p.

BRODERICK, G.A. Methodology for the determining ruminal degradability of feed proteins. In: SIMPÓSIO INTERNACIONAL SOBRE EXIGÊNCIAS NUTRICIONAIS DE RUMINANTES, 1995, Viçosa, MG. Anais... Viçosa, MG: Universidade Federal de Viçosa, 1995. p.139-176.

BRODERICK, G.A.; YANG, J.H.; KOEGEL, R.G. Effect of steam heating alfalfa hay on utilization by lactating dairy cows. Journal of Dairy Science, v.76, n.1, p.165-174, 1993.

BURRITT, E.A.; PFISTER, J.A.; MALECHEK, J.C. Effect of drying method on the nutritive composition of esophageal fistula forage samples: influence of maturity. Journal of Range Management, v.41, n.4, p.346-349, 1988

COCHRAN, W.G.; COX, G.M. Experimental designs. 2.ed. New York: Jonh Willey \& Sons, 1957. 611p.

DETMANN, E.; CECON, P.R.; PAULINO, M.F. et al. Estimação de parâmetros da cinética de trânsito de partículas em bovinos sob pastejo por diferentes seqüências amostrais. Revista Brasileira de Zootecnia, v.30, n.1, p.222-230, 2001.

DETMANN, E.; PAULINO, M.F.; CECON, P.R. et al. Níveis de proteína em suplementos para terminação de bovinos em pastejo durante o período de transição seca/águas: consumo voluntário e trânsito de partículas. Revista Brasileira de Zootecnia, v.34, n.4, p.1371-1379, 2005a.

DETMANN, E.; PAULINO, M.F.; VALADARES FILHO, S.C. et al Níveis de proteína em suplementos para terminação de bovinos em pastejo durante o período de transição seca/águas: Digestibilidade aparente e parâmetros do metabolismo ruminal e dos compostos nitrogenados. Revista Brasileira de Zootecnia, v.34, n.4, p.1380-1391, 2005b.

FRANCE, J.; DHANOA, M.S.; SIDDONS, R.C. et al. Estimating the fecal producing by ruminants from faecal marker concentration curves. Journal of Theoretical Biology, v.135, n.2, p.383-391, 1988.

IIYAMA, K.; LAM, T.B.T.; MEIKLE, P.J. et al. Cell wall biosynthesis and its regulation. In: JUNG, H.G.; BUXTON, D.R.; HATFIELD, R.D. et al. (Eds.) Forage cell wall structure and digestibility Madison: American Society of Agronomy, 1993. p.621-684.

LICITRA, G.; HERNANDEZ, T.M.; Van SOEST, P.J. Standardization of procedures for nitrogen fractionation of ruminant feeds Animal Feed Science and Technology, v.57, p.347-358, 1996

LIPPKE, H.; ELLIS, W.C.; JACOBS, B.F. Recovery of indigestible fiber from feces of sheep and cattle on forage diets. Journal of Dairy Science, v.69, n.2, p.403-412, 1986.

MUSCATO, T.V.; SNIFFEN, C.J.; KRISHNAMOORTHY, U. et al. Amino acid content of noncell and cell wall fractions in feedstuffs. Journal of Dairy Science, v.66, n.10, p.21982207, 1983.

NAKAMURA, T.; KLOPFENSTEIN, T.J.; BRITTON, R.A Evaluation of acid detergent insoluble nitrogen as an indicator of protein quality in nonforage proteins. Journal of Animal Science, v.72, n.4, p.1043-1048, 1994a.

NAKAMURA, T.; KLOPFENSTEIN, T.J.; GIBB, D.J. et al. Growth efficiency and digestibility of heated protein fed to growing ruminants. Journal of Animal Science, v.72, n.3, p.774782, $1994 \mathrm{~b}$.

NATIONAL RESEARCH COUNCIL - NRC. Nutrient requirements of dairy cattle. 7.ed. Washington: Academic Press, 2001. 381p.

NELSON, D.L.; COX, M.M. Lehninger principles of biochemistry. 3. ed. New York: Worth Publishers, 2000. 1152p.

SNIFFEN, C.J.; O'CONNOR, J.D.; Van SOEST, P.J. et al. A net carbohydrate and protein system for evaluating cattle diets: II. Carbohydrate and protein availability. Journal of Animal Science, v.70, n.11, p.3562-3577, 1992

SOUZA, G.S. Introdução aos modelos de regressão linear e não-linear. Brasília: EMBRAPA-SPI, 1998. 505p.

UDÉN, P.; COLUCCI, P.E.; VAN SOEST, P.J. Investigation of chromium, cerium and cobalt as markers in digesta. Rate of passage studies. Journal of Science and Food Agriculture v. 31, n.7, p.625-632, 1980

Van SOEST, P.J. Nutritional ecology of the ruminant. 2.ed. Ithaca: Cornell University Press, 1994. 476p.

Van SOEST, P.J.; ROBERTSON, J.B. Analysis of forages and fibrous foods. Ithaca: Cornell University, 1985. 202p.

WATERS, C.J.; KITCHERSIDE, M.A.; WEBSTER, A.J.F. Problems associated with estimating the digestibility of undegraded dietary nitrogen from acid-detergent insoluble nitrogen. Animal Feed Science and Technology, v.39, n.3/4, p.279-291, 1992.

WILLIANS, C.H.; DAVID, D.J.; IISMA, O. The determination of chromic oxide in faeces samples by atomic absorption spectrophotometry. Journal of Agricultural Science, v.59, n.3, p.381-385, 1962.

YANG, J.H.; BRODERICK, G.A.; KOEGEL, R.G. Effect of heat treating alfalfa hay on chemical composition and ruminal in vitro protein degradation. Journal of Dairy Science, v.76, n.1, p.154-164, 1993. 